\title{
La función social del beber en los pueblos andinos prehispánicos
}

\author{
Eduardo Estrella
}

Universidad Central. Quito (Ecuador)

A través de las fuentes etnohistóricas, se estudian las conexiones de la bebida con el hombre andino, y más en concreto, ecuatoriano, tanto en su mundo personal como en la comunidad a la que pertenece. Se centra en la época prehispánica, basándose en los cronistas Cobo, Cieza y el Inca Garcilaso.

\section{Introducción}

Cuenta la tradición de los indios cañaris de la región andina norte, recogida por el padre Bernabé Cobo, que únicamente dos hermanos se salvaron del diluvio universal, viviendo en la cima del monte Huacayñan. Una vez pasada la hecatombe, todos los días salían a buscar raíces y hierbas para aplacar su hambre, y un día que retornaron a su morada "la hallaron abastecida de diversos manjares y abundancia de chicha”. Sucedía que mientras los hermanos estaban fuera, llegaban volando dos aves, que una vez transformadas en hermosas mujeres, les preparaban la comida y la chicha. Tras descubrirse el misterio, los hermanos decidieron atrapar a las doncellas, antes que retornaran a su primitiva condición de aves; así procedieron y después las convencieron de que fueran sus esposas y así surgió la raza cañari. '

La chicha es un elemento sustancial de la cosmogonía y de los mitos genéticos de muchos pueblos andinos, y una rápida revisión de las fuentes etnohistóricas, referidas sobre todo a la zona ocupada por el actual Ecuador, nos demostrará la existencia de un beber vinculado a la vida del hombre y de la comunidad, a sus esfuerzos por dominar la naturaleza, a su lucha por buscar una explicación de la vida, la muerte, la existencia del mundo y de las cosas.

1 Cobo, Bernabé: Historia del Nuevo Mundo. 1553. Madrid, 1964, Vol. Il, pág. 151. 
¿Cumplió el consumo de alcohol alguna función en la sociedad andina prehispánica? ¿Cuál fue el significado y la trascendencia del beber? ¿Es posible encontrar en los actuales pueblos indígenas andinos, remanencias de los antiguos modos de beber y de sus significados?

Para responder a estas preguntas es necesario encontrar un nexo entre el comportamiento humano y la cultura. Así, si en términos de cultura, fuera preciso definir al ser humano, diríamos siguiendo a Cassirer, que una característica básica del hombre es su función simbólica. La creación del símbolo transforma la totalidad de la vida humana, y desde ese momento el hombre ya no vive únicamente en una realidad, que cada vez se le hace más amplia, sino, lo que es más importante, vive en una dimensión distinta de la realidad. El ser humano existe no solamente en un ámbito físico, sino en universo simbólico, dice Cassirer. El lenguaje, el mito, el arte, la religión, son desde su creación por el hombre, elementos de este universo, que van conformando los hilos que entretejen la red simbólica, que constituye la complicada urdimbre de la experiencia humana. En adelante, todo pensamiento y toda experiencia, refuerzan y hacen cada vez más compleja esta red. ${ }^{2}$

Sobre esta base, y entendiendo la cultura como los procedimientos y resultados de la actividad humana, los valores creados por ella, observamos que desde su nacimiento los individuos se encuentran bajo la influencia de una determinada cultura, donde se dan ya por conocidos ciertos objetos, están formados muchos valores, establecidas varias normas de convivencia y organizados determinados conjuntos de ideas. A través de la experiencia y el conocimiento, el hombre adquiere los elementos básicos de su propia cultura, asimila sus valores y acepta las pautas de conducta dominantes.

La cultura se transmite de generación en generación, no sólo como elemento de información, sino como ingrediente básico de la formación de la personalidad. Asimismo su impronta se deja sentir en la estructuración de las organizaciones sociales y en los pro-

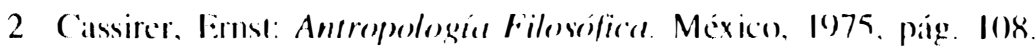


cesos desarrollados para la obtención de los productos que necesita la cada vez más exigente vida del hombre.

¿Puede ser catalogado el consumo de alcohol como un comportamiento cultural y ser analizado desde una perspectiva histórica? Sí, más aún en el sentido con el que pretendemos estudiar este problema. No nos referimos a un acontecimiento circunstancial, individual, dependiente de la exclusiva voluntad del hombre, en el beber identificamos una íntima relación con elementos como la comunicación, el lenguaje, el mito, la religión, el arte, las creencias. Entre el beber y estos aspectos constitutivos de la cultura hay un vínculo funcional; por esta razón al igual que se busca la función básica del mito, el arte, la religión, es necesario identificar la función del beber, mucho más allá de sus manifestaciones externas simples. ${ }^{3}$

Si hablamos del beber como un comportamiento cultural, la interpretación de su funcionalidad es compleja. Señala Levi-Strauss, que los fenómenos culturales tienen una naturaleza inconsciente, lo que significa "que la actividad inconsciente del espíritu, consiste en imponer formas a un contenido, y si estas formas son fundamentalmente las mismas para todos los espíritus antiguos y modernos, primitivos y civilizados, sería necesario y suficiente alcanzar la estructura inconsciente que subyace a cada institución o a cada costumbre, para obtener un principio de interpretación válida para otras instituciones y otras costumbres”. ¿Cómo identificar esa estructura? Para esto Levi-Strauss propone la convergencia del método etnológico y el método histórico, modelo que pretendemos aplicar en la búsqueda de una explicación al beber en la época prehispánica. ${ }^{4}$

En síntesis, el consumo de alcohol considerado como un comportamiento cultural, es aprendido por los individuos en el curso de su vida práctica, pasando a integrarse a su conciencia social, es de-

3 Ihíde'm. págs. 1(18-120). Ver también Pagés Larrayal, F.: "Modos Culturales del Be-

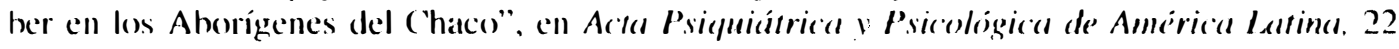
(1), 1976, págs. 21 45, y Estrellat, Eduardo: "C 'ultura y Alcohol", en Estrellit, E. Ed.: Estrediess ale Sallud Me'ntal, Quito, 1982, prigs. 127 I60).

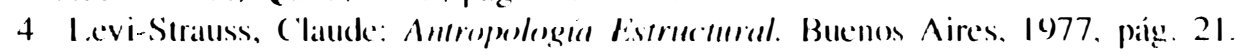


cir, tiene la posibilidad de repetirse, mientras la idea del mundo que tienen los individuos de un grupo social, sea vivida como una experiencia. ${ }^{5}$ En este sentido, el estudio de la función del beber en la sociedad ecuatoriana prehispánica, puede aportar datos no sólo para conocer la situación pasada, sino también para explicar el significado de los modelos de consumo de alcohol en las actuales poblaciones aborígenes del país.

El beber formó parte de la cosmología y cosmogonía aborigen, cumplió funciones relacionadas con el trabajo, la generación de prestigio, la consolidación o adquisición de status, la transmisión de conocimientos, el mantenimiento de las creencias mágico-religiosas, la determinación y recordación de las épocas de paso en el ciclo vital de los individuos, etc.

Nos vamos a referir a tres modelos básicos del beber: ceremonial, transfigurante y estimulante.

\section{Modo de consumo ceremonial o ritual}

Este es un patrón de consumo comunitario o familiar, articulado a las más importantes tradiciones de la organización social. Este beber ritual cumplía varias funciones, entre las que destacamos las siguientes:

\section{a) Función de refuerzo de la visión del mundo}

El aborigen andino organizó una cosmovisión en la cual el mundo fue construido por un donador, entidad superior que regulaba la existencia del hombre y de las cosas; el hombre estaba conformado por cuerpo y espíritu, siendo este último el más significativo; la naturaleza estaba vivificada, manteniendo por lo tanto una consaguinidad con la existencia humana. Sobre esta matriz se expresaron los mitos de origen y todos los aspectos de la vida social del aborigen.

5 Pagés Larraya, F.: "Modos Culturales del...". 
De todos los productos de la tierra, el maíz fue un elemento clave para la supervivencia de las poblaciones americanas, y entre los pueblos andinos, este cereal tuvo tal categoría, que se creyó fue donado por una entidad superior, por un Creador; así lo consigna el cronista Cobo:

"Los indios de las Provincias de Quito refieren que vino el hacedor por la mar del Norte, que atravesó toda la tierra criando hombres, repartiendo provincias y distribuyendo lenguajes (...) y fingen deste Criador mil disparates (...), que rompía la tierra con la punta de una vara y luego quedaban cultivadas y dispuestas para sembrarse, y que, con sola su palabra, hacía nacer el maíz y las demás legumbres". ${ }^{6}$

El maíz era importante, no sólo como alimento sino como bebida, ya que de él se hacía un licor fermentado llamado chicha, que era ritualmente utilizada en la adoración de la tierra, el sol y los dioses tutelares. Para reproducir la relación del hombre con el más allá, se ofrendaba chicha en las ceremonias funerarias. Así entre los manteños de la Costa, según Cieza:

"junto a las tumbas ponían comida y cántaros de su vino de maíz (...) Hecho esto, ponían encima de la sepultura una caña de las gordas (...) y como son estas cañas huecas, tenían cuidado a sus tiempos de le echar deste brebaje que ellos llaman azua hecho de maíz y de otras raíces; porque, engañados del demonio, creen y tienen por opinión (según yo entendí de ellos) que el muerto bebe deste vino que por la caña le echan".

El maíz fue un objeto ritual imprescindible para las antiguas comunidades indígenas del Ecuador. Así lo refieren varios informantes de los primeros tiempos de la colonia. En el tiempo de la "infidelidad", los indios de Quilca, en la actual provincia de Imbabura: "adoraban al cielo y a los cerros más altos y nevosos" mediante "sacrificio de maíz blanco, y de chicha y de coca". ${ }^{8}$ Los paltas de

6 Cobo, Bernabé: Historia del Nuevo Mundo..., Vol. II, pág. 150.

7 Cieza de León, Pedro: Crónica del Perú. (1550). Madrid, 1962, pág. 161.

8 Jiménez de la Espada, Marcos, Ed.: Relaciones Geográficas de Indias. Lima y Madrid, 1965. Vol. II, pág. 246. 
Loja, adoraban al sol y a la luna: "quemando maíz y otros mantenimientos". 9

Según cuenta Garcilaso de la Vega, los Incas adoraban al sol:

"Ofreciéndole en sacrificio mucho brebaje de lo que bebían, hecho de agua y maíz, y en las comidas ordinarias cuando las traían de beber, (...) mojaban la punta del dedo de en medio y mirando al cielo con acatamiento despedían del dedo. como quien da capirotes, la gota del brebaje que en él se les había pegado, ofreciéndole al sol en acinamiento [acción] de gracias porque les daba de beber, que era entre aquellos indios señal de adoración". ${ }^{10}$

Los acontecimientos importantes de la vida del pueblo, de la familia y del imperio, se celebraban consumiendo chicha. ${ }^{11}$

La tecnología utilizada para elaborar la chicha fue variada, la forma más simple consistía en mezclar harina de maíz con agua y permitir el proceso de fermentación. Con el objeto de conseguir un mayor grado alcohólico y mejorar el sabor, se aplicaban procedimientos que tenían como finalidad la conversión de los almidones del maíz en azúcar. Una enzima, la diastasa, estimula este cambio, y la forma más común de diastasa para la elaboración de la chicha era la saliva. Las chichas de maíz o de yuca que se hacían previa masticación del producto, seguían este principio. Maltear, es decir, remojar el grano y dejarlo hasta que se inicie el proceso de fermentación, es otra forma de conseguir diastasa. ${ }^{12}$ La preparación de la chicha de "jora" —un subproducto del maíz-, que hasta la actualidad es común en las poblaciones andinas, sigue este sistema. Estas técnicas básicas se modificaban localmente, con el objeto de mejorar la bebida, así, se añadía una especia, el ishpingo (Ocotea quixos Lam.) o frutas como la piña.

9 Salinas de Loyola, Juan: "Relación de la Ciudad de Zamora de los Alcaides, (1573)", en Jiménez de la Espada, Ed.: Relaciones Geográficas..., Vol. III, págs. 125-135. pág. 77.

10 Vega, Garcilaso de la, El Inca: Comentarios Reales (1609). Lima, 1971. Vol. I,

11 Valdizan, Hermilio y Ángel Maldonado: La Medicina Popular Peruana. Lima, 1922, Vol. II, pág. 75.

12 Cutler, Hugh y Martín Cárdenas: "La Chicha, una Cerveza Sudamericana Indígena", en Lechtman y Soldi, A. M., Eds.: La Tecnología en el Mundo Andino, México, 1981, págs. 247-259. 


\section{b) Beber ceremonial y transmisión de las tradiciones comunitarias}

A través del consumo ceremonial, se mantienen y transmiten las creencias y tradiciones, de generación en generación. Los pantzaleos de la Sierra central del Ecuador actual, según referencia de Cieza,

"Tenían gran cuidado de hacer sus areitos y cantares ordenadamente, asidos hombres y mujeres de las manos y andando a la redonda a son de sus atambores, recontando en sus cantares y endechas las cosas pasadas y siempre bebiendo hasta quedar muy embriagados". ${ }^{13}$

En el cantar indígena se transmitían los mitos y leyendas grupales, se representaban las grandes luchas por las que debió pasar la comunidad para alcanzar su situación actual.

\section{c) Beber Ceremonial y ciclo vital}

Este beber se relacionaba con épocas importantes del ciclo vital de los individuos; el nacimiento, la edad de corte de pelo (5-6 años), la pubertad, el compromiso matrimonial, el casamiento y la muerte.

Entre los quijos de la Amazonía, cuando nacía un niño, la madre no debía entrar en casa por algunos días, y el padre tenía que ayunar, lo que significaba sostenerse únicamente con chicha de yuca; sólo así el niño se mantenía con vida y podía crecer sano y vigoroso. ${ }^{14} \mathrm{El}$ padre Paz Maldonado, que vivió entre los puruháes a fines del siglo XVI, refiere que cuando un niño cumplía cinco o seis años, le ponían un nombre, mediante el siguiente ritual: "los padres del muchacho o muchacha, con unas tijeras llévanlo de casa en casa, y en cada casa le dan una tijerada hasta que lo trasquilan todo y después le ponen un nombre y hacen una fiesta con

13 Cieza de León, P.: Crónica del..., pág. 136.

14 Ortegón, Diego de: Descripción de la Gobernación de Quixos, Sumaco y La Canela, 1577, en "Cuadernos de Historia y Arqueología”, 23 (40). Guayaquil, 1973, páginas. 3-27. 
bebida". ${ }^{15}$ Esta ceremonia de corte de pelo, que significaba el paso del niño a la vida del trabajo, era común entre los pueblos andinos y es una práctica que hasta hoy se puede observar en numerosas comunidades indígenas.

El compromiso matrimonial era otra ocasión para beber. El mismo Paz Maldonado informó que entre los puruháes:

"Cuando se aficiona algún indio de alguna india que sea doncella o dueña, vase a prima noche a casa de sus padres, y lleva leña y paja y chicha; llama y salen los padres de la moza y díseles que el quiere bien a su hija, que se la den, que allí trae leña para que se caliente y paja para que se acueste y chicha para que beba, que se la de por mujer, que el les servirá y hará sus rozas, y guardará su puerta y hará otros servicios". ${ }^{16}$

El casamiento se celebraba siempre con un gran ceremonial en donde nunca faltaba el favor de la bebida. Entre los cañaris por ejemplo, según testimonio de Cieza:

"Los Señores se casan con las mujeres que más quieren [pero] una era la principal (...), hacían gran convite, en el que después que han comido y bebido a su voluntad, hacen cosas a su uso". ${ }^{17}$

La muerte y el ritual funerario constituían otra gran oportunidad para expresar el dolor mediante el consumo de bebida. Como hemos anotado, entre los manteños, cuando alguien moría, depositaban en su tumba comida y cántaros de chicha, y no se contentaban con eso, sino que colocaban encima de la sepultura una caña hueca, e introducían en ella un poco de licor de cuando en cuando, pensando que el muerto estaría con sed y deseo de chicha. ${ }^{18} \mathrm{Tam}$ bién en los rituales funerarios de los puruháes se consumía chicha en cantidad, especialmente si el que moría era un principal; el acto terminaba con un "baile y una solemne borrachera". ${ }^{19}$

15 Maldonado, Juan de Paz: "Descripción del pueblo de Sant Andrés de Xunsi (1582)", en Jiménez de la Espada, M., Ed.: Relaciones Geográficas..., Vol. II, págs. 55-162.

16 Ibidem.

17 Cieza de León, P.: Crónica del..., pág. 145.

18 Ibídem.

19 Ibidem, nota 15. 


\section{d) Beber Ceremonial y rituales agrarios}

El vínculo entre el beber y el ciclo agrícola, fue de gran importancia en los pueblos andinos prehispánicos. El ritual dedicado al cultivo de una planta, era proporcionalmente más complejo, como las dificultades que entrañaba su cuidado; por esta razón, mientras más inquietud y zozobra existía en el grupo acerca de la productividad de una planta, más complicados eran los ceremoniales destinados a su protección. En el caso andino, el maíz fue un producto que requirió grandes cuidados. La siembra, el crecimiento y la cosecha se acompañaban de rituales donde el consumo de alcohol era un elemento imprescindible; así por ejemplo, en San Andrés de Xunxi, en la Sierra Norte, un testigo vio lo siguiente:

"Cuando el maíz está ya cuajado, hacen una gran borrachera y arman a un indio dispuesto a uso de guerra, el cual va con sus armas y con una honda por los cerros que hay alrededor y dando voces, diciendo que si hay alguno que se quisiera matar con él que venga, y como no hay nadie que le responda, vuelve victorioso a la borrachera y dice que el campo está seguro, y luego él y los demás beben hasta que se emborrachaban, victoriosos de que tienen su maíz ya granado". ${ }^{20}$

El cultivo del maíz requirió un gran esfuerzo humano y una naturaleza propicia, provocando ansiedad y preocupación, que se cristalizó en numerosos rituales. Garcilaso cuenta lo siguiente de los Incas:

"Como el maíz era el principal sustento de los indios y el hielo su principal enemigo, le temían mucho; y así, cuando era tiempo que podía atacarlos, suplicaban al sol, con sacrificios, fiestas y bailes y gran bebida, mandase al hielo que no les hiciese daño". ${ }^{2 !}$

En el Perú, Murra ha llamado la atención sobre la existencia de dos sistemas agrícolas andinos: uno referido al maíz, que servía de alimento y de objeto ceremonial y por eso tenía gran prestigio,

20 Ibidem.

21 Vega, Garcilaso de la, El Inca: Comentarios..., Vol. II, pág. 17. 
y otro para el cultivo de tubérculos de altura. El cultivo del cereal se convirtió en un asunto importante para el estado: "El mismo Rey inauguraba la temporada de siembra; en el día apropiado se dirigía a los andenes de maíz del sol para roturar la tierra en la que se sembraría el grano para los sacrificios, con su talla con punta de oro". ${ }^{22}$

Los Incas utilizaban el maíz como gran don para solicitar favores a sus dioses; así reverenciaban a la "mamapacha" [la tierra], derramando chicha y maíz molido, a tiempo de las siembras, pidiendo les diese buenas cosechas. Las plantas y las mazorcas especiales, eran tenidas como "canopas", es decir, eran objetos familiares de adoración; estas "canopas" se llamaban "zaramamas" o madres del maíz. ${ }^{23}$

El calendario agronómico Inca y el ritual de la bebida iban siempre de la mano.

\section{Beber transfigurante}

En los pueblos andinos, la adoración de sus dioses tutelares, la solicitud de una actitud favorable para con el hombre, se impregnaban de alcohol. Los sacerdotes del culto aborigen y ocasionalmente la comunidad entera, bebían con el objeto de transmutar su ser, modalidad de consumo que hemos llamado "transfigurante", ${ }^{24}$ en la cual se hace evidente un elemento cultural de carácter configuracional, "cuya finalidad es obtener una naturaleza sagrada mediante la ceremonia socializante del beber, que otorga la posibilidad de participar de un universo mítico, que entraña la dualidad de lo numinoso, es decir del infinito gozo y del terror paralizante". ${ }^{25}$

22 Murra, John S.: Formaciones Económicas y Políticas del Mundo Andino. I.ima. 1975, pág. 45, y del mismo autor, La Organización Económica del estado Inca. México, 1978, pág. 46.

23 Arriaga, Pablo José de: "Extirpación de la Idolatría en el Perú (1621)". en (iri. nicas Peruanas de Interés Indégena. Madrid, 1968, págs. 2()1-211.

24 Estrella, Eduardo: "Cultura y...", págs. 127-160.

25 Pagés Larraya, F.: “Modos Culturales del...”, págs. 21-45. 
El historiador ecuatoriano González Suárez, al analizar esta situación, señala:

"[el indio], cuando se regalaba embriagándose con los licores fermentados que solía preparar adoraba primero a su chicha, y la saludaba con efusión, diciéndole requiebros y donaires amorosos: Rubia, tú me alegras, sosténme y hazme que goce de sueños y visiones apacibles". ${ }^{26}$

Este beber transfigurante tuvo muchas veces relación con el consumo de drogas alucinógenas, en rituales comunitarios y en ceremonias de adivinación y curativas.

Por estudios etnológicos realizados en comunidades andinas actuales, se ha logrado encontrar remanentes de este modelo de consumo. ${ }^{27}$ Así, entre los indígenas de Cangahua, en la Sierra norte del actual Ecuador, el 29 de junio, día de San Pedro, festividad cristiana sobrepuesta sobre una antigua celebración indígena del cambio del solsticio y la presencia de los primeros frutos, aflora un nuevo espíritu en el indígena oprimido; es otro: luchador, valiente, guerrero. No se siente solo, sabe que todos los miembros de su grupo participan en la fiesta, y que también quieren obtener otro ser, surgiendo entre todos, renovados ya, una unidad férrea, momentánea, donde se puede identificar un simbólico proceso de reivindicación. La bebida es parte sustancial de la fiesta, y en la chicha y el alcohol el hombre encuentra un espíritu vivificador, transformador. Se bebe para cambiar, para transfigurarse. Así describe este proceso un autor del lugar:

"Los campesinos madrugan antes del despunte del alba, a vestirse de los clásicos arreos, que dejaron días atrás abandonados en las Pachas [lugares sagrados| para que se penetren del misterioso hálito de la naturaleza. Con estas prendas el hombre va llenándose de fuerzas ex-

26 González. Suárez, Federico: Historia del Ecuador (1890). Quito, 1969. Vol. II, pág. 156.

27 Estrella, Eduardo: "Modos Culturales de ('onsume de alcohol en una población campesina de la provincia de Pichincha”, en Eduardo Estrella, Ed.: Estudios de Salud..., páginas. 162-176. 
trañas, del espíritu belicoso de sus antepasados, demostrando en el grito robusto que lanza a los cuatro vientos, para que entiendan cuantos le escuchan, que se halla a punto de comenzar San Pedro; contempla el sol que empieza a brillar sobre las cumbres del Cayambe y erguido soberanamente, abre los temerarios brazos en el deseo de vivificarse plenamente del ardor del dios de sus mayores, zapatea con todo el vigor que sus piernas formidables lo permiten, con el propósito de comprobar que se halla poseído de un genio poderoso y de la potencia enérgica del cosmos" 28

\section{Beber estimulante}

El progresivo aumento de población, los procesos de expansión en busca de mejores tierras, la producción para el mantenimiento de la comunidad, obligan a las organizaciones sociales andinas a una intensificación del trabajo y a una mayor utilización de la fuerza laboral para compensar las deficiencias tecnológicas. El trabajo cooperativo, herencia de las antiguas formas de relación tribal, es un elemento clave para el desarrollo de los pueblos andinos prehispánicos. Minga se denomina en la Sierra norte, al sistema de trabajo cooperativo en el que participan los miembros de la comunidad, y la minga tiene un doble aspecto, la labor de colaboración comunitaria y el carácter festivo. ${ }^{29}$ Una minga es impensable sin la presencia de la chicha. El alcohol entonces, actúa como elemento estimulante y aglutinador en el proceso de trabajo, ya que a medida que se va efectuando la labor, se consume chicha y la jornada concluye con baile, canto y bebida.

Al hablar de las mingas de los Incas, señala el historiador González Suárez, que las faenas de labranza se convertían en fiestas y regocijos,

"y la chicha se repartía con prodigalidad suma, alegraba los ánimos y hacía terminar en ruidosa algazara y borrachera común toda reu-

28 Tamayo, C. A.: Monografía de Cangahua. Quito, 1972, pág. 20.

29 Guevara, Darío: Las Mingas en el Ecuador. Quito, 1957, pág. 16. 
nión para el trabajos de los campos. El estímulo para el trabajo ha de ser siempre su vehemente propensión a la bebida". ${ }^{30}$

Mediante las mingas se laboró la tierra, se construyeron terrazas, templos, ciudades, caminos, puentes, etc. Esta gran utilización de la fuerza de trabajo humano, necesariamente se acompañaba del estímulo de la chicha. Jaramillo Alvarado dice que el trabajo agrícola, antes que una labor monótona, constituía una fiesta, la chicha corría a torrentes - anota-: "y graves crónicas dicen que la borrachera era consentida y fomentada por las autoridades. Desde luego que el trabajo era obligatorio, lo mismo que el tributo. Los meses del año estaban marcados por las fiestas, en las que se bebía y bailaba con fervor". ${ }^{31}$

La bebida, en este contexto, cumplía también otra función, al facilitar la sociabilidad y la recreación. Refiere Valcárcel —citado por Guevara - que el "grupo entero se movilizaba en ánimo festivo. La tarea ceremonial esperada ansiosamente, es una ocasión de la más franca e intensa sociabilidad; se come y se bebe, se baila y se canta con intensa efusión, mientras se desempeña la empresa". Además, según este autor:

"Muy fácil debía resultar la extensión del trabajo a otras actividades de claro beneficio para el grupo: la limpieza de las acequias de regadío, el arreglo de los caminos, la construcción de viviendas, etc. Pero cuando el grupo rompe el horizonte doméstico y se incluye en una sociedad grande, en el vuelco de la conciencia particularista, al sentido de la gran comunidad, no pierde su hábito para trabajar por el bien de todos. El Inca trazará el camino de mil leguas y serán las comunidades aledañas quienes ejecutarán sin sacrificio. Y así el templo, el palacio, las terrazas, el granero del estado, las fortalezas, los canales de riego, la tumba real, el convento de las escogidas". ${ }^{32}$

Todo trabajo es posible, si de por medio está la comunicación social del grupo y el estímulo socializante y energético de la chicha.

30 González Suárez, Federico: Historia del..., Vol. II, pág. 225.

31 Jaramillo Alvarado, Pío: El Indio Ecuatoriano, quito, 1954, pág. 21.

32 Ibidem, nota 29. 


\section{Conclusión}

El estudio del consumo de alcohol en los pueblos andinos prehispánicos, debe tomar en cuenta la funcionalidad y los significados que adquiría, dentro de una matriz social organizada para el trabajo y el cumplimiento de las normas señaladas, y dentro de un modo especial de ver el mundo. De esta manera, se podrá apreciar la existencia de varios modelos de consumo, cada uno de los cuales tenía una función social específica. 